\title{
Investigating facial features of four types of laughter in historic illustrations
}

\author{
Willibald Ruch \\ Jennifer Hofmann \\ Tracey Platt \\ University of Zurich, Switzerland
}

\begin{abstract}
This study investigates the facial features of different laughter types in historic illustrations. Several conceptually different types of laughter were proposed in the historic literature, but only four types were represented in visual and verbal illustrations by four or more historic illustrators (joyful, intense, schadenfreude laughter, grinning). Study 1 examined the encoding of facial features in 18 illustrations by the Facial Action Coding System and study 2 investigated the decoding by laypeople. Illustrations of laughter involving a Duchenne Display (DD) were perceived as joyful irrespective of their initial classification. In intense laughter, the intensity of the zygomatic major muscle predicted the perception of intensity, but not the proposed changes in the upper face. In fact, "frowning" seemed to be antagonistic to the perception of joy. Schadenfreude and grinning did not have high recognition rates. Going along with the idea that schadenfreude is either a blend of a positive and negative emotion, or solely joy with attempts of masking it, it may entail additional features beyond the DD. Grinning was best represented by low intensity laughter, narrowed eye aperture and mouth prolonging actions. So far, only the DD could be reliably morphologically differentiated and recognized, supporting Darwin's proposal of joyful laughter being the laughter prototype.
\end{abstract}

Keywords: laughter, types, FACS, Darwin, expression of emotion, Duchenne Display

Ruch and Ekman's (2001) overview on the knowledge about laughter (respiration, vocalization, facial action, body movement) illustrated the mechanisms of laughter, and defined its elements. While acknowledging that more variants of this expressivecommunicative signal might exist, they focused on the common denominators of all forms. Still, they proposed distinguishing between laughing spontaneously (emotional laughter) and 
laughing voluntarily (contrived or faked laughter). Even with a sharp increase in research on laughter and its application during the past decade, two fundamental questions remain: Do different types of emotional laughter exist, and how are they distinguishable on a morphological basis, especially when looking at their facial features?

Laughter variations or types are assumed to be determined by the type of eliciting stimulus (e.g., an unexpected hoax, tickling), the social situation (e.g., being with friends or an authority figure), habitual/dispositional (e.g., body constitution, personality traits) and current affective (e.g., motivational states, emotions), organismic (e.g., fatigued, intoxicated, energetic), and cognitive (e.g., awareness of situational demands, appropriateness of display rules) factors. If such variations exist, they will be encoded into language (e.g., "hearty" or "nervous" laughter), apparent in the different systems (e.g., vocalization, facial expression, body motion), and there will be different antecedents and social and affective consequences. Variations not only occur due to differences in spontaneous laughter but also due to voluntary attempts to regulate spontaneous laughter, which require consideration when aiming to classify laughter. Qualitative differences can be the core of such classifications (rather than mere quantitative differences; e.g., in duration), but it is questionable whether these are based on morphological differences (i.e., different muscular involvement). Categories may just be artifacts, emerging from different perspectives: For example, the laughing person might experience amusement at a person's mishap, the "target person" might perceive it as "mean" and an observer as "malicious". Thus, one laughter, which is expressed with a certain set of facial and vocal features, might be encoded in the language with different labels. Leaving the question unanswered whether the variety of terms linking to laughter actually correspond to morphologically distinct types of laughter.

Ruch (1990, 1993) found laughter occurring in response to humorous stimuli and general joy, suggesting a link to the Duchenne Display (Ruch, 1993). The Duchenne Display (DD) is characterized by a joint and symmetric contraction of zygomatic major muscle and orbicularis oculi pars orbitalis muscle, and is the only reliable facial signal for joy (Ekman, Davidson, \& Friesen, 1990; Frank \& Ekman, 1993). Consequently, Ruch (1990, 1993) argues that the difference between smiling and laughter may be a difference in intensity of the emotion of amusement/exhilaration. Still, laughter is a more complex behavior than smiling. Not only facial parameters but lacrimation, respiration, body movements (e.g., Hall \& Allin, 1897), body posture and vocalization must be considered. Different authors (Keltner, 1995; Keltner \& Bonanno, 1997; Ruch, 1993) defined the basis of joyful/amused laughter (Duchenne laughter) consisting of the DD plus an audible, laughter-related vocalization and an open mouth. Yet, the exact number of muscles remains unclear: Sumitsuji (1967) claimed laughter involves a further six muscles. Laughter also includes the relaxation of some muscles (masseter, pterygoids), leading to jaw lowering and oral air expulsion (Ruch \& Ekman, 2001). Thus, there is agreement on the existence of amusement/joyful laughter and its respective facial display.

A definitive number of laughter qualities remain elusive. Yet a recent review of the historic literature (Huber, 2011) shows that authors of the $19^{\text {th }}$ and early $20^{\text {th }}$ century (e.g., Piderit, 1867; Darwin, 1872) made numerous attempts at distinguishing different qualities of laughter. Although these sources did not specialize on laughter, but on emotion or the presentation of emotion (e.g., as a guide to actors, Borée, 1899), several types of laughter qualities were described. As no current research team is paying attention to the field of laughter qualities, it is of interest as to what can be learned from the descriptions of these historic authors. As a selection criterion, all authors describing at least two different qualities of laughter were included in the current study. The work of 11 historic authors claiming the existence of up to 10 different laughs was scrutinized (Piderit, 1867; Darwin, 1872; Schack, 
1890; Borée, 1899; Heller, 1902; Rudolph, 1903; Huter, 1925; Lersch, 1932; Herland, 1938; Leonhard, 1950; Strehle, 1954). They included variants of laughter characterized by emotional and motivational qualities, intensity and regulation of laughter, depicting personality traits, and also evaluative labels (e.g., "silly" laughter). Among those authors, the painter Rudolph (1903) was unique as he additionally considered different blends and mental states (e.g., "curious", "observant" laughter) allowing him to arrive at 46 combinations; i.e., the highest number of laughter illustrations in the literature. Most of the authors provided visual illustrations (photography, drawing, sculptures, woodcut carvings). Sometimes, the presumed muscular basis or descriptions of changes in the face were supplied and the latter only partly corresponds with current knowledge (e.g., the risorius muscle was considered responsible for the upward and backwards drawing of the mouth corners and lifting of the cheeks which is actually created by the zygomatic major). Only occasionally the authors discuss the rationale for distinguishing the types of laughs and what methods they used. These include free observation, inspecting posed laughter, a priori determining of muscles involved and describing consequent facial actions (Huber, 2011). In total, the population of proposed laughter types consisted 10 (or 57 if one counts the inflated variations proposed by Rudolph, 1903). These 10 were further scrutinized and the application of several criteria reduced them to four (joyful laughter, intense laughter, schadenfreude laughter and grinning) that were finally included in the empirical study. Criteria were that the proposed laughter categories a) were available in visual illustration and b) verbal descriptions, and c) that the category was proposed by more than three illustrators to allow for comparisons.

Joyful laughter is the prototype of laughter. For Darwin (1872), laughter is the natural and universal expression of joy. "Joy, when intense, leads to various purposeless movements to dancing about, clapping the hands, stamping, etc., and to loud laughter. Laughter seems to be the expression of mere joy or happiness" (p. 198). Drawing on the work of Duchenne (1862), Darwin (1872) and Piderit (1867) gave a detailed and mostly accurate description of joyful laughter, both at the level of the muscular involvement as well as descriptions of appearance changes. It involves the contraction of the zygomatic major muscle, with wrinkles emerging at the mouth corners, the cheek being lifted up, and the mouth being widely opened. In the upper face, the contraction of the orbicularis oculi pars orbitalis muscle, which leads to wrinkling at the outer corners of the eye, is reported. From a current perspective one can summarize that they proposed laughter involving a DD (and the opening of the mouth) with the additional element of lifting the upper lip (by the levator labii superioris muscles). Ekman (1998) more recently disagreed to the latter, suggesting that the raise of the upper lip sometimes seen in stronger expressions is due to the strong contraction or the zygomatic major muscle

Even though labels differ (e.g., "hearty", "happy" laughter), all other historic authors describe a type of laughter expressing positive affect (consequently labeled joyful laughter for this study). Thus, there are ample illustrations for investigating the facial ingredients of this prototype of laughter. The descriptions of the muscular basis and of facial changes occasionally varies; and this will allow to examine whether deviations from the DD occur in the illustrations and whether they appear to be valid or distorting the perception of the laughter as being joyful.

Many authors discussed intense laughter, occasionally labeling it "strong", "excessive", "strongly pronounced," or even "violent" laughter. Obviously, the intensification of joyful laughter will be characterized by the shared muscles being more strongly contracted (and the facial changes being more pronounced) than during strong laughter. This is in line with the graduation hypothesis by Darwin (1872) who proposed that “... a graduated series can be followed from violent to moderate laughter, to a broad smile, to a gentle smile, and to the 
expression of mere cheerfulness" (p. 208). However, in the footsteps of Bell (1844) and Piderit (1867), Darwin (1972) proposed that during strongly pronounced or violent laughter also the corrugator muscle is contracted, causing a frown. This element has been picked up by further authors (e.g., Heller, 1902) and the very intense laughter expression was said to be highly similar to crying (Piderit, 1867; Lange, 1937). The resemblance may be due to a long duration of intense laughter, which can be embarrassing or hurtful (Darwin, 1872; Heller, 1902; Piderit, 1867; Plessner, 1950). As a third variant of intensification of laughter, Heller (1902) and Dearborn (1919) suggested that in intense laughter all facial muscles are contracted to a certain degree.

Schadenfreude laughter was illustrated often as well. The term expresses the pleasure derived from the misfortunes of others-when the enemy has suffered. Some authors proposed that schadenfreude is an emotion blend, namely one of a positive and negative emotion, or basing on other person-related variables (such as lowered intelligence, e.g., Rudolph, 1903). More specifically, some authors see schadenfreude as a blend of joy and anger or taunt and perhaps gratification (Kemper, 1987; Szameitat et al., 2009). Ekman (2003) considers schadenfreude one of 16 enjoyable emotions, which are all expressed by the DD. As its expression is not considered appropriate in all cultures, one might see attempts to suppress or conceal it.

Grinning is considered a fake laughter and is often discussed along with laughter types, although it is questionable whether it involves a vocalization in humans (in mammals, however, "grin-and-shriek" patterns involving glottal closures and exhalations likely to produce vocalizations are described; e.g., Andrews, 1965; Fridlund, 1994). While Huter (1925) considered grinning as an expression of malice, Boree (1899) viewed it as an expression of stupidity or faked laughter. Darwin (1872) wrote that “... the mouths of some very short-sighted persons, who are forced habitually to reduce the aperture of their eyes, wear from this same reason a grinning expression" (p. 150). From Darwin's writing one can summarize that grinning is characterized by (or at least contain he elements of) a retraction of the lip corners, a lifting of upper lips so that the teeth are exposed and a reduced eye aperture.

The aim of this study is to investigate claims made by historic authors to see whether past knowledge can add to the still open and under-investigated question of whether different qualities of laughter exist. The claims on joyful and intense laughter as well as other claims on schadenfreude and grinning are investigated in two studies, utilizing the work of historic authors. Study 1) facial features coding study aims at identifying facial codes for four selected categories of laughter (joyful laughter, intense laughter, schadenfreude, and grinning) by first applying FACS to the available historic illustrations and evaluating whether there is one or more valid prototypes for that category. Study 2) agreement rating study investigates whether the four categories as such (or at least subtypes found in study 1) can be correctly assigned by laypeople.

\section{Study 1 - Facial features coding}

\section{Method}

\section{Selection of the stimuli}

From the population of existing laughter illustrations in historic literature (consisting of photographs, drawings, reprinted woodcut carvings, and photographs of sculptures), illustrations were chosen according to several criteria: the type of laughter needed to be 
existent in a verbal description as well as visual illustration, and more than three authors needed to agree on the existence of this laughter to allow for comparisons. Consequently, 18 illustrations remained from the original pool (Piderit, 1867; Borée, 1899; Heller, 1902; Rudolph, 1903; Huter, 1925), showing the only four types of laughter that met all criteria (see Figure 1).

\section{Joyful Laughs}
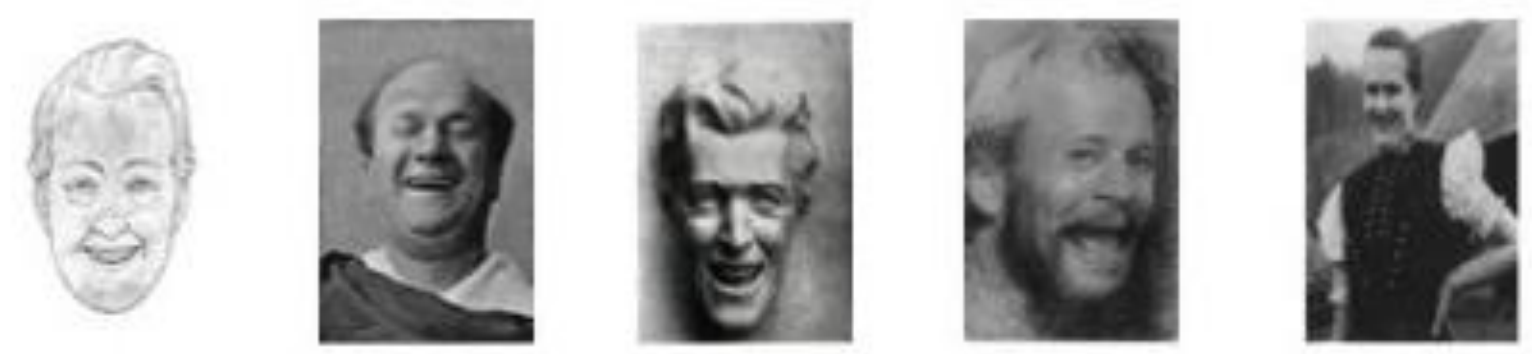

\section{Intense Laughs}
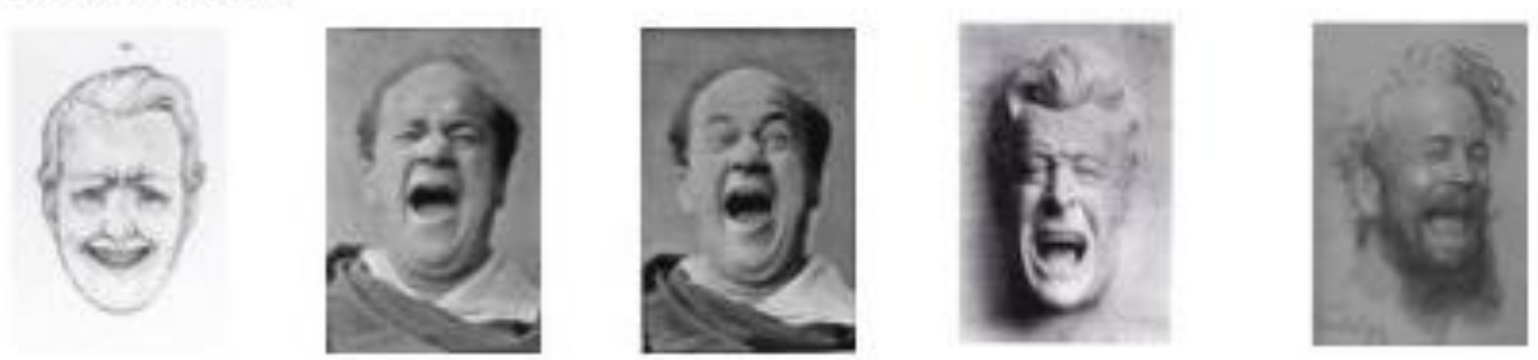

\section{Schadenfreude Laughs}
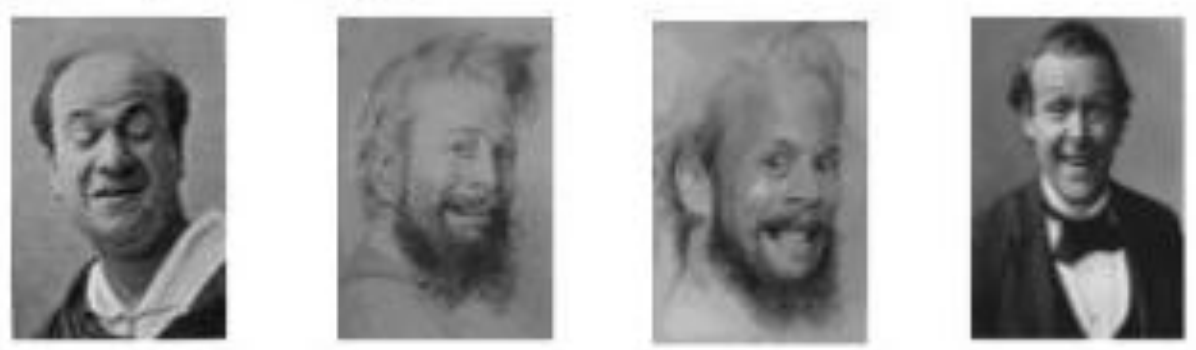

\section{Grinning}
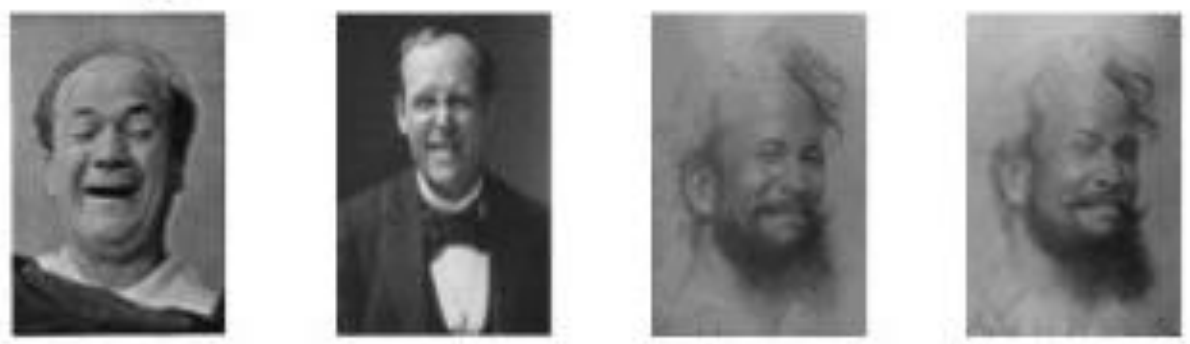

Figure 1. Joyful Laughs (from left to right): Piderit, Borée, Heller, Rudolph, Huter. Intense Laughs: Piderit, Borée No. 1 and No. 2, Heller, Rudolph. Schadenfreude Laughs: Borée, Rudolph No. 1 and No. 2, Huter. Grinning: Borée, Huter, Rudolph No. 1 and No. 2. 
As Figure 1 shows, the joyful laughter was described and illustrated by five authors (five illustrations; Huter calling it "genuine and friendly" laughter), and there were five illustrations of intense laughter (two by Boree). There were four examples each of schadenfreude laughter (two by Rudolph) and of grinning (two by Rudolph). Of the 18 visual illustrations, there were eight photographs (Huter and Borée), six drawings (Rudolph), two woodcuts (Piderit), and two photographs of sculptures of facial expression (Heller).

\section{Facial Measurements}

The 18 illustrations were coded with the Facial Action Coding System (FACS; Ekman, Friesen, \& Hager, 2002). The FACS is an anatomically based method allowing the coding of 44 visually discernible action units (AU), which are coded in frequency, intensity, timing, duration, laterality, symmetry and co-occurrence with other AU's. The intensities range from trace (coded as A) to maximum (E, no further stretching, bulging, pouching, etc., is possible). Conservative coding rules for the coding of still pictures, as suggested by Ekman, Friesen and Hager (2002), were applied.

\section{Procedure}

The 18 illustrations were coded with FACS by two of the authors of the current study who were blind to the initial meaning of the illustration and who coded independently from each other. All AU's were coded for intensity and symmetry. Furthermore, the changes of head and eye position (AU54, 61, 63, 64) were coded in a yes/no format. The inter-rater reliability was computed by the formula of Ekman, Friesen and Hager (2002) and yielded to a satisfactory agreement of $87 \%$. Discrepancies in the FACS-coding were discussed, involving two further FACS-certified coders until full consensus about the coding was obtained.

\section{Results}

Altogether 14 AU's and 6 head and eye movements and positions were detected. All illustrations entailed an AU12 (contraction of the zygomatic major muscle) and the AU25 (Lips Part). Table 1 presents the FACS codes of the 18 laughter illustrations grouped by category and in chronological order. 
European Journal of Humour Research1(1)

Table 1. FACS-coding of joyful laughter, intense laughter, schadenfreude laughter, and grinning.

\begin{tabular}{|c|c|c|c|c|c|c|c|c|c|c|c|c|c|c|c|c|c|}
\hline \multirow[b]{2}{*}{ Laughter qualities } & \multicolumn{17}{|c|}{ Action Units (AUs) } \\
\hline & 1 & 2 & 4 & 5 & 6 & 7 & 9 & 12 & 15 & 17 & 20 & 24 & 25 & 26 & 27 & 43 & $\mathrm{H} \& \mathrm{E}$ \\
\hline \multicolumn{18}{|l|}{ Joyful } \\
\hline Piderit (1867) & & & & & B & & & $\mathrm{C}$ & & & & & $\mathrm{C}$ & $\mathrm{B}$ & & & \\
\hline Borée (1899) & & & & & $\mathrm{C}$ & $\mathrm{C}$ & & $\mathrm{C}$ & & & & & $\mathrm{C}$ & $\mathrm{C}$ & & & 58 \\
\hline Heller (1902) & & & B & & $\mathrm{C}$ & $\mathrm{C}$ & $\mathrm{RB}$ & $\mathrm{C}$ & & & & & $\mathrm{C}$ & $\mathrm{B}$ & & & \\
\hline Rudolph (1903) & & & & & $\mathrm{C}$ & $\mathrm{D}$ & & $\mathrm{D}$ & & & & & $\mathrm{D}$ & $\mathrm{D}$ & & & 52,62 \\
\hline Huter (1925) & & & & & & & & $\mathrm{C}$ & & & & & $\mathrm{C}$ & & & & 58,63 \\
\hline \multicolumn{18}{|l|}{ Intense } \\
\hline Piderit (1867) & & & $\mathrm{D}$ & & $\mathrm{B}$ & $\mathrm{B}$ & & $\mathrm{D}$ & & & & & $\mathrm{D}$ & $\mathrm{C}$ & & & \\
\hline Borée No. 1 (1899) & & & $\mathrm{C}$ & & & & $\mathrm{C}$ & $\mathrm{C}$ & & & & & $\mathrm{D}$ & $\mathrm{D}$ & & $\mathrm{E}$ & \\
\hline Borée No. 2 (1899) & & $\begin{array}{l}\mathrm{LB} \\
\mathrm{RC}\end{array}$ & & $\mathrm{C}$ & & $\mathrm{C}$ & & $\mathrm{C}$ & & & & & $\mathrm{D}$ & & $\mathrm{D}$ & & \\
\hline Heller (1902) & & & $\mathrm{C}$ & & $\mathrm{D}$ & $\mathrm{C}$ & $\mathrm{C}$ & $\mathrm{D}$ & & & & & $\mathrm{D}$ & & $\mathrm{D}$ & & \\
\hline Rudolph (i) (1903) & & & & & $\mathrm{D}$ & $\mathrm{D}$ & & $\mathrm{D}$ & & & & & $\mathrm{D}$ & & $\mathrm{C}$ & & 52,62 \\
\hline \multicolumn{18}{|l|}{ Schadenfreude } \\
\hline Borée (1899) & B & $\mathrm{RD}$ & & & & $\mathrm{D}$ & & $\mathrm{C}$ & $\mathrm{RC}$ & & & & $\mathrm{B}$ & B & & & \\
\hline
\end{tabular}


Rudolph No. 1 (1903)

Rudolph No. 2 (i) (1903)

Huter (1925)

\section{Grinning}

Borée (1899)

C

Rudolph No. 1 (1903)

Rudolph No. 2 (i) (1903)

Huter (1925)
B B

B

C

B C

B

B $\quad$ B

52,62

D C

B $\quad$ B

C

C

B

B

C $\quad \mathrm{C}$

B

C

C

Notes. AU = Action Unit. H\&E = Head and Eye Positions/Movements. AU1 = Inner Brow Raiser. AU2 = Outer Brow Raiser. AU4 = Brow Lowerer. AU5 = Upper Lid Raiser. AU6 = Cheek Raiser. AU7 = Lids Tight. AU9 = Nose Wrinkle. AU12 = Lip Corner Puller. AU15 = Lip Corner Depressor. AU17 = Chin Raiser AU20 = Lip Stretch. AU24 = Lip Presser. AU25 = Lips Part. AU26 = Jaw Drop. AU27 = Mouth Stretch. AU43 = Eye Closure. AU52 = Head Turn Right. AU58 = Head Back. AU62 = Eyes Right. AU63 = Eyes Up. A-E = indicate intensity of the AU $(\mathrm{A}=$ trace, $\mathrm{B}=$ slight, $\mathrm{C}=$ marked, $\mathrm{D}=\mathrm{extreme}, \mathrm{E}=$ maximum $) . \mathrm{L}=$ left side of the face (protagonist view). $\mathrm{R}=$ right side of the face (protagonist view). All AU descriptions and features after Ekman, Friesen and Hager (2002). (i) $=$ intense. 
Table 1 shows that of the five illustrations of joyful laughter, three illustrations can be considered DDs (Piderit, Rudolph, Borée) and two cannot, albeit for different reasons (Heller, Huter). The former three all involve the symmetric action of the AU6 and AU12 (i.e., the two action units that define the DD) plus various degrees of mouth aperture or jaw position (i.e., AU25, AU26, and AU27), which may accompany a DD without changing its nature. The intensity of the AU12 ranged from marked to extreme (AU12C and AU12D) and the AU6 ranged from slight (i.e., B) to marked (i.e., C). Two of the illustrations also involved an AU7 (Lid Tightener, narrows the eye aperture), and eye-and head movements.

Of the two non-DDs, Huter's illustration lacks the AU6. This laughter involves the AU12D and AU25C, as well as AU58 (Tilt Back) and AU63 (Eyes Up). While the illustration by Heller contains both AU6 and AU12, it also involves elements that transcend the DD; there was a slight AU4 (Brow Lowerer) and a slight AU9 (Nose Wrinkler) on the right-hand side of the face only. The AU4 and AU9 are both markers for negative affect, such as anger in the case of AU4 and disgust in AU9 (e.g., Ekman 2003).

With regard to the five illustrations for intense laughter, Rudolph's illustration was the only one showing a DD; both AU12 and AU6 were of an extreme intensity, and the mouth was stretched (i.e., AU27) as compared to merely a relaxed jaw drop. The four other illustrations contained added features in the upper face; three (Piderit, Heller, Borée No.1) involving "frowning" (i.e., AU4; Heller and Borée No.1 also AU9) in at least marked intensity, and one (i.e., Borée No.2) involved wrinkles on the forehead (i.e., AU1, AU2), raised upper eyelids (AU5), and tightened the lower eyelid (i.e., AU7). It is noteworthy that Borée (who introduced two forms of intense laughter) used AU26 for his "roaring laughter," and AU27 for the "most intense laughter". The two posed illustrations by the actor Borée lacked the AU6, while Piderit and Heller involved an AU6 (and AU7).

The analysis of the illustrations for each of these authors providing both joyful and intense laughter illustrations and comparing them to the joyful laughter, made two further changes apparent in the intense laughter. First and foremost, the intensity is displayed in the mouth opening since with one exception, the intensity increased for the AU25 (all extreme now), and the jaw opening (intensity of all AU26 increased, if not changing to AU27). Second, the AU6 and AU12 increased for one intensity level in two illustrations each (but still none exceeded level D).

There is no convergence in the illustrations of the schadenfreude laughter. However, some features are apparent. First, there is typically an AU12 in a mid-level intensity (i.e., C), together with an AU25 and AU26 (of even lower intensity) and no AU27. When there is an AU6 (as in both illustrations by Rudolph), it is of slight intensity (i.e., B), and in the three cases of an AU7 the intensity is either slight or extreme. Thus, in all cases the intensity of AU6, AU7, AU25, und AU26 was different from the one of AU12. In the illustrations with regular intensity (Borée, Rudolph No.1, Huter), there is always an AU2, and in the high intensity schadenfreude laughter there is an AU4 (but no AU2).

Borée's (1899) schadenfreude illustration is most unique and differs from the others in both the composition of the AUs involved as well as their intensity and symmetry/laterality. The mouth corners are being simultaneously affected by opposite actions, albeit different for each side of the face: on the right-hand side, the RAU15C (Lip Corner Depressor) counteracts the action of the AU12C. Furthermore, there is unilateral activity in the upper face, with the outer eyebrows raised only on the right side (RAU2D). Moreover, the extreme intensity of two actions (AU2, AU7) is superimposed on otherwise low and mid-range intensity features (e.g., AU1B, and mouth actions). Rudolph's two illustrations of schadenfreude are portrayed as differing in intensity, with the more intense one being higher in AU5, AU12, AU25, and 
AU26. Additionally, the intense form contains an AU4 and AU7, but in opposition to the slight form, there is no AU2, AU17B (Chin Raiser) and AU20B (Lip Stretcher).

The grinning displays were very heterogeneous and none met the criteria for coding a DD (as in one case the AU6 was missing and in the others, additional AUs were added to AU6 and AU12). Borée's illustration differed most from the other illustrations since it not only shows a raising of the eyebrows (AU1 and AU2), a pressing of the lips (AU24), but also no AU6 (but a very and intense AU7). The other three illustrations share the characteristic of small mouth apertures (i.e., low intense AU25, but not AU26 or AU27). All contained an AU12 of marked intensity and contraction of both parts of the orbicularis oculi with AU7 being even more intense than AU6 in one illustration. All three have an AU4; again in low (slight and marked) intensity. However, there were differences too. Both of the illustrations of grinning that Rudolph provided included an AU17 (slight and marked in the more intense illustration of grin), in addition, Huter's illustration additionally entailed an AU9.

\section{Discussion}

Clearly, none of the laughter and grinning types studied in this analysis of historic illustrations yielded identical FACS codes. Nevertheless, prototypes and variants were identified, and unique illustrations also occurred. Whether any single variant is a valid type or whether the types cluster to expression families, cannot be decided at this point. Maybe some of the illustrations were based on wrong hypotheses on the side of the respective authors (e.g., in the woodcut carvings and the sculptures; or actors aiming at expressing a certain display). This will have to be investigated in a decoding study. In the following discussion, hypotheses about of putative prototypes and variants will be formed.

As expected, the DD played a central role in the historic illustrations of joyful laughter, although none of the authors made reference to the involvement of only two muscles. Three of the five illustrations fulfilled the criteria for a DD (Borée, Piderit, Rudolph), namely the AU6 (possibly also AU7) and AU12, possibly AU25 and AU26, but no other AU's were present. Interestingly, even Piderit's carvings did not transcend the facial features of the DD, although his writings empathize the involvement of a few more muscles (risorius, depressor anguli oris, zygomatic minor and levator labii superioris muscle), suggesting AU10, AU11 and AU20 to occur in the expression of joyful laughter. Interestingly, Piderit did not mention the AU6, although he clearly carved the crows feet and a deep infraorbital fold. Likewise, Darwin's assumption of the involvement of the levator labii superioris did not get any support, as no other indicator of an AU10 was present; the rise of the upper lip was a byproduct of the contraction of the zygomatic major muscle.

The AUs added by Heller (AU4 and AU9) to the joyful laughter correspond well with his descriptions of the facial changes. However, there was no fit with the muscles he listed. Heller seems to have made two mistakes. First, he assumed that the orbicularis oculi creates bulges and furrows on the sides of the nose and across the root of the nose (which they do not) and these give the impression of an AU9. Second, he added vertical furrows on the forehead and had the inner portion of the eye brows lowered (which gives the impression of an AU4) although this - according to both his description of the facial changes and the list of muscles (corrugator muscle) — should only occur during intense laughter. Again, Heller saw the risorius muscle as the major laughing muscle, but no AU20 could be coded. As the AU4 and AU9 are considered negative markers of emotions, it will be of interest, whether this illustration will still be assigned to the category of joyful laughter.

Huter's joyful laughter illustration contained no AU6. Huter described his illustration as a "friendly" and "frank" laughter, and presenting a "cheerful" person. He also described it as 
not being faked but "natural". In retrospect, we have to admit that due to the ascribed naturalness of laughter, we were perhaps a bit over inclusive when integrating this photo within the category of joyful laughter. Huter himself did not mention joy as an emotion accompanying this laugh (but attributed cheerfulness to the person). Most likely, this laughter gives more of the impression of a social and friendly laughter (due to the head and eye position to the side and up) or shyness (due to the sideway glance).

The most apparent change for intense laughter is the wider opening of the mouth. This is reflected in higher intensity of the AU25, the higher intensity of AU26 or the presence of AU27 rather than AU26. This indicates the more forceful exhalation in intense laughter. The AU6, AU7 and AU12 were of the same intensity, or one level higher. There was no evidence that during intense laughter all facial muscles are active to a certain extent (Dearborn, 1919; Heller, 1902), but three variants of intensifying the laugh (aside of the wider mouth aperture) can be observed. First, there is higher intensity of the DD (Rudolph). Second, there is the addition of the frowning (Piderit, Heller, Borée No.1) to the upper face, and third Borée (No.2) added a brow raise. Only one variant stays in the definition of a DD; the other two transcend it. Most illustrations followed the Piderit-Darwin hypothesis of a corrugator muscle activity during intense laughter. The actor Borée apparently assumed that adding the AU1 and AU2 enhances the intensity of the laugh. However, Borée was also the only author who did not produce an AU6 in his acting. It will require moving pictures to see when these putative signs of intense laughter appear and disappear on the face during actual laughter. As these were all static illustrations, one cannot judge whether these are emblems, illustrators, blends of emotions, artificial expressions posed without actually feeling an emotion, or accidental movements. Study 2 (agreement rating study) will give an indication which of the three variants will be perceived higher in intense laughter and higher in joyful laughter.

Finally, Heller's sculpture uniquely involved an AU9. As indicated above, Heller assumed that the contraction of the orbicularis oculi produces wrinkles at the side and the root of the nose, thus he sculpted wrinkles that were then coded as AU9 with a marked intensity.

For neither the schadenfreude nor the grinning illustrations a pure DD was coded. In fact, only unique expressions were put forward and they were accompanied by a variety of AUs. For the schadenfreude laughter, a small aperture of the mouth seemed to be characteristic (indicating a less forceful laughter exhalation or a down-regulated intensity due to display rules) and also the eye region showed unequal, usually lower (in one case higher) intensity of the AU12. Most frequently an AU2 could be observed. Furthermore, Borée had an additional AU15, and Rudolph added AU17 and AU20. Both these actions help counteract the effects of the contraction of the zygomatic major and orbicularis oculi muscles, i.e., they distort the expression of joy. This, in conjunction with the low(ered) intensity might help giving the appearance of that one is not really enjoying the mishaps of others in an unmitigated way. While this is compatible with the view that schadenfreude is a facet of joy (Ekman 2003), but down-regulated (lowered intensity) and concealed (additional AUs) due to lower cultural acceptance (in the encoder), it is doubtful whether or not decoders will identify it as such.

In general, grinning illustrations seem to have in common that the mouth aperture is comparably smaller and the jaw does not relax/lower. This is in line with the description that grinning may or may not be accompanied by any utterance of sound but if it does, it is not a dominant element. In fact, there was no lowering of the jaw (AU27) visible in grinning, and only once an AU26 was present. Another salient element is the AU7 in a high intensity; occasionally higher than AU6 (that was missing in one case altogether) and AU12. This is in line with Darwin's observation, that grinning entails a smaller eye aperture. Several types of illustrations of grinning were observed, with Borée's raising of the eyebrows, pressing of the 
lips and semi-closed eyelids being the most unique. The others involved frowning and either a chin raise or a wrinkling of the nose. Grinning is connoted with appearing malicious or stupid (Borée, 1899; Huter, 1925) and hence it would not be surprising if variants existed. It should be highlighted that some of the assumptions of these authors were not confirmed. For example, Rudolph (1903) mentioned the lifting of the upper lip (i.e., that Darwin attributed to the levator labii superioris muscle) in grinning, but no separate AU10 was found in the coding. Likewise, Huter's descriptions of facial changes that typically could be explained by the contraction of the buccinator muscle on one side of the face were not confirmed as no unilateral AU14 was coded in grinning at all.

\section{Study 2 - Agreement rating study}

It is expected that in this decoding study participants recognize joyful laughter better if it exclusively contains a DD. Laughter is expected to be identified as intense if the DD is more intense and/or if it involves a frowning in addition to the AU12 and AU6. Given the heterogeneity of the schadenfreude and grinning expressions it is difficult to put forward a hypothesis which features will facilitate the recognition of the expression. In fact it is difficult to predict if any of the expressions will be perceived as containing schadenfreude or grinning. Nevertheless, the laughter will be perceived as representing schadenfreude, if the facial expression unites positive and negative markers. A grin is expected to be recognized a such if it contains a retraction of the lip corners, a lifting of upper lips so that the teeth are exposed and a reduced eye aperture.

\section{Method}

Participants -The sample consisted of 85 German-speaking adults with an age range from 19 to 46 years $(M=23.56, S D=5.67)$. Five participants were excluded from the analysis because they had completed less than $80 \%$ of the survey.

\section{Instrument and procedure}

The 18 illustrations depicting joyful, intense, and schadenfreude laughter as well as grinning were presented in random order. Participants rated on a five-point scale $(1=$ not at all, $2=$ somewhat, 3 = mostly, 4 = intensely, 5 = very intensely) how prototypical an illustration is for each of the four categories. Additionally, alternative interpretations of the nature of the expression could be given in a designated box.

Volunteers were recruited through leaflets and mailing lists and received a link to the webpage of the study. They were told that the presented illustrations were formed between 1880 and 1930 and that the study aims at finding out whether nowadays people can still identify the nature of the laughs.

\section{Results}

For each of the 18 illustrations means and standard deviations for all four ratings were computed. Furthermore, alternative interpretations given to an illustration were counted and the most representative examples were determined. Each nomination given by more than three participants is listed in Table 2 . 
Table 2. Friedman Tests and Wilcoxon Signed Rank Order Comparisons with agreement to the four types of laughter as dependent variable and the four types as repeated measures to the 18 illustrations.

\begin{tabular}{|c|c|c|c|c|c|c|c|c|c|c|c|}
\hline \multirow[t]{2}{*}{ Author and Category } & \multicolumn{2}{|c|}{ Joyful laughter } & \multicolumn{2}{|l|}{$\begin{array}{l}\text { Intense } \\
\text { laughter }\end{array}$} & \multicolumn{2}{|c|}{$\begin{array}{l}\text { Schaden- } \\
\text { freude } \\
\text { laughter }\end{array}$} & \multicolumn{2}{|c|}{ Grinning } & \multirow[b]{2}{*}{$\begin{array}{c}\chi^{2} \\
(d f=3)\end{array}$} & \multirow[b]{2}{*}{ Nr. } & \multirow[b]{2}{*}{$\begin{array}{l}\text { Representative } \\
\text { interpretation }\end{array}$} \\
\hline & $M$ & $S D$ & $M$ & $S D$ & $M$ & $S D$ & $M$ & $S D$ & & & \\
\hline Joyful laughter & & & & & & & & & & 26 & \\
\hline Piderit (1867) & 3.76 & 0.92 & 2.07 & 0.88 & 1.16 & 0.44 & 2.38 & 1.26 & & 2 & \\
\hline Borée (1899) & 3.64 & 1.06 & 4.05 & 0.97 & 2.01 & 1.19 & 1.31 & 0.63 & & 4 & contrived, posed \\
\hline Heller (1902) & $2.47 \mathrm{ab}$ & 1.21 & $2.72 \mathrm{a}$ & 1.17 & $2.62 \mathrm{a}$ & 1.37 & $2.11 \mathrm{~b}$ & 1.04 & 12.11 & 8 & scornful \\
\hline Rudolph (1903) & 3.39 & 1.28 & 4.53 & 0.80 & 2.65 & 1.41 & 1.41 & 0.88 & & 2 & \\
\hline Huter (1925) & $3.30 \mathrm{a}$ & 1.08 & $1.92 b$ & 1.02 & $1.27 \mathrm{c}$ & 0.53 & $3.03 \mathrm{a}$ & 1.40 & 101.44 & 10 & arrogant, posed \\
\hline Intense laughter & & & & & & & & & & 65 & \\
\hline Piderit (1867) & $1.67 \mathrm{c}$ & 0.81 & $2.05 b$ & 1.06 & $3.21 \mathrm{a}$ & 1.36 & $2.65 b$ & 1.24 & 49.27 & 8 & contrived, skeptical \\
\hline Borée (1899) No.1 & $2.43 b$ & 1.38 & $4.08 \mathrm{a}$ & 1.35 & $2.62 b$ & 1.47 & $1.30 \mathrm{c}$ & 0.75 & 105.79 & 25 & sneezing, surprise, yawning \\
\hline Borée (1899) No.2 & $1.34 b$ & 0.65 & $1.79 \mathrm{a}$ & 1.14 & $2.19 \mathrm{a}$ & 1.29 & $2.34 \mathrm{a}$ & 1.30 & 30.34 & 12 & $\begin{array}{l}\text { crying, disgust, distressed, } \\
\text { painful }\end{array}$ \\
\hline Heller (1902) & $1.14 b$ & 0.42 & $3.23 \mathrm{a}$ & 1.61 & $3.15 \mathrm{a}$ & 1.63 & $1.15 b$ & 0.46 & 108.43 & 16 & angry, malicious, screaming \\
\hline Rudolph (1903) (intense) & 3.41 & 1.24 & 4.45 & 0.86 & 2.08 & 1.28 & 1.33 & 0.72 & & 4 & \\
\hline
\end{tabular}




\section{Schadenfreude laughter}

\begin{tabular}{|c|c|c|c|c|c|c|c|c|c|c|c|}
\hline Borée (1899) & 1.74 & 0.94 & 1.43 & 0.70 & 3.07 & 1.43 & 2.75 & 1.18 & & 12 & $\begin{array}{l}\text { contempt, disparaging, } \\
\text { spiteful }\end{array}$ \\
\hline Rudolph No. 1 (1903) & 1.53 & 0.86 & 1.28 & 066 & 2.04 & 1.10 & 2.91 & 1.30 & & 24 & $\begin{array}{l}\text { forced, insecure, posed, } \\
\text { surprised }\end{array}$ \\
\hline Rudolph No. 2 (i) (1903) & 1.86 & 0.98 & 2.62 & 1.21 & 2.62 & 1.46 & 1.99 & 1.22 & & 13 & fearful, fear evoking \\
\hline Huter (1925) & 2.66 & 1.04 & 1.61 & 0.77 & 1.31 & 0.60 & 2.82 & 1.25 & & 14 & dazzled, disgusted, forced \\
\hline Grinning & & & & & & & & & & 36 & \\
\hline Borée (1899) & $3.03 \mathrm{a}$ & 1.24 & $3.19 \mathrm{a}$ & 1.26 & $2.10 \mathrm{~b}$ & 1.25 & $1.78 b$ & 0.99 & 58.85 & 2 & \\
\hline Rudolph No. 1 (1903) & $1.72 b$ & 1.00 & $2.07 \mathrm{a}$ & 1.31 & $2.11 \mathrm{a}$ & 1.23 & $2.41 \mathrm{a}$ & 1.25 & 15.65 & 13 & crying, in pain, sad \\
\hline Rudolph No. 2 (i) (1903) & $2.48 b$ & 1.33 & $3.90 \mathrm{a}$ & 1.41 & $2.21 b$ & 1.20 & $1.19 \mathrm{c}$ & 0.52 & 119.65 & 8 & painful, screaming, yawning \\
\hline Huter (1925) & $1.34 \mathrm{c}$ & 0.61 & $1.23 \mathrm{c}$ & 0.57 & $1.85 b$ & 1.11 & $2.48 \mathrm{a}$ & 1.36 & 15.65 & 13 & $\begin{array}{l}\text { contrived, insecure, } \\
\text { surprised }\end{array}$ \\
\hline
\end{tabular}

Notes. $\mathrm{N}=72-80 . \mathrm{Nr} .=$ Total of alternative interpretations given. $\chi^{2}=$ Friedman Chi Square. All main effects were significant $\mathrm{p}<.01 . \mathrm{a}>\mathrm{b}>\mathrm{c}>\mathrm{d}$ indicate significant results of Wilcoxon rank order comparisons (adjustment: Bonferroni). Representative alternative explanations were listed when being mentioned more than three times. (i) $=$ intense. 
Table 2 shows that the mean values of the four laughter type ratings (joyful, intense, schadenfreude laughter and grinning) ranged from 1.14 to 4.53. Considering a cut-off score of 3.00 (i.e., on average the rated quality as "mostly applying"), one can say that seven of the illustrations have no (main) quality that mostly applies; lowering the cut-off point to 2.50 (between somewhat and mostly applying), there are still four illustrations that are not clearly categorized by the participants. On the positive side, six of the illustrations were considered to be joyful laughter (cut-off value of 3.00), and four of these actually were illustrations of joyful laughter. Joyful laughter also had the lowest number of alternative interpretations. Seven illustrations depicted intense laughter and three of the five illustrations of intense laughter were among them. One of the schadenfreude illustrations reached the cut-off score for the schadenfreude laughter as did two more of the intense laughter category did. Finally, only one illustration was considered to be grinning and that stemmed from the joyful laughter category.

\section{The perception of joyful laughter}

A repeated measures ANOVA was computed with the prototypicality of joyful laughter as the dependent variable and the five illustrations of joyful display as the repeated measurement factor. The overall effect was significant $(F[4,292]=16.63, p<.001)$. More importantly, planned comparisons indicated that the three DD based laughter types (Piderit, Borée, and Rudolph) were judged as significantly more typical for joyful laughter than Huter's illustration, which lacked the AU6 $(F[1,292]=4.07, p<.05)$, and even more so compared to Heller's illustration that added an AU9, $(F[1,292]=62.01, p<.001)$. Also these two differed $(F[1,292]=22.88, p<.001)$ showing that signs of negative emotions reduce the value of joyful laughter more than the lack of eye involvement. Considering all DDs, also the illustration of an intense laughter by Rudolph contained a DD. A planned comparison showed that this intense laughter illustration did not differ from the three joyful DD laughter illustrations regarding ratings joyful laughter $(F[1,219]=2.03$, n.s. $)$.

The way in which the two illustrations with no DD (Heller, Huter) were perceived, was inspected more closely by comparing the four ratings for each illustration individually. Since sphericity and/or normality assumptions were violated, the non-parametric Friedman test was used. Subsequently, Bonferroni corrected post hoc tests (Wilcoxon Signed Rank Tests) were performed. The Chi-square values for both main effects were significant (see Table 2). Heller's (1902) joyful laughter was perceived as being equally typical for intense $(M=2.72$, $S D=1.17)$, schadenfreude $(M=2.62, S D=1.37)$ and joyful $(M=2.47, S D=1.21)$ laughter. Typical alternative interpretations covered elements of scornfulness and maliciousness. Huter's non-Duchenne version of joyful laughter was perceived equally typical for joyful $(M$ $=3.30, S D=1.08)$ laughter and grinning $(M=3.03, S D=1.40)$. These two ratings were uncorrelated $(r=.11, \mathrm{~ns})$. Thus, there are not two subgroups rating either for joyful laughter or for grinning. The alternative interpretations of this illustration entailed posed laughter, proud, arrogant, skeptical, shy, superficial, and polite laughter, as well as benevolent laughter.

\section{Perception of Intense laughter}

Three displays of intense laughter yielded intensity scores of > 3.0, namely Rudolph, Borée and Heller, with only the latter being a DD laughter. Several hypotheses regarding the perception of intensity were tested. First, the four DD laughs ( 3 from the joyful category, one from the intense category) were rank-ordered according to the intensity of the elements (lip corner retraction, involvement of eyes, aperture of mouth). Indeed, the perception of intensity 
raised from low to high; Borée's illustration (AU6C, AU7C, AU12C, AU25C, AU26C) was perceived as much more intense than Piderit's illustration (AU6B, AU12C, AU25C, AU26B; $F[1,219]=217.69, p<.001$ ), but lower than Rudolph's joyful laughter (AU6C, AU7D, AU12D, AU25D, AU26D; $F[1,219]=13.24, p<.001)$. However, there was no increase from Rudolph`s joyful laughter to his intense laughter (AU6D, AU7D, AU12D, AU25D, AU27C; $F[1,219]=.37$, n.s.); thus, the change from AU6C to AU6D, and from AU26D to AU27C did not yield any noticeable increment.

Second, the intense laughter illustration involving a DD was tested against the three intense laughter illustrations involving an AU4, and turned out as being perceived significantly less intense $(F[1,288]=76.82, p<.001)$. Also, Borée's second variant of intense laughter was perceived less intense compared to the intense DD $(F[1,288]=205.56$, $p<.001)$. Thus, none of variants including further AU's exceeded the intensity perception of the intense DD laughter. Finally, the pairs of joyful and intense laughter were compared for each of the authors. There was no difference between joyful and intense laughter for Piderit's illustrations. In Borée's illustrations, no difference in perceived joyfulness was found, and there was even a decrease in perceived intensity for Borée No. $2(F[1,236]=5.31, p<.01)$. Only for Heller's two illustrations a significant increment in perceived intensity was obtained $(F[1,158]=4.62, p<.05)$; while both are not seen to be joyful, the illustration of more intense laughter is indeed perceived as more intense. Friedman tests were computed for the four intense laughter illustrations that did not contain a DD individually and turned out to be significant (see Table 2). Subsequent post hoc tests showed that for Piderits's and Heller's intense laughter (both containing AU4) the schadenfreude ratings were higher than the ones for joyful. Also Borée's (No. 1) illustration contained an AU4 but schadenfreude and joyfulness ratings did not differ (but are higher than grinning and lower than intense laughter). In Piderit's and Heller's display of intense laughter, the appearance of schadenfreude is present and this might be due to the shared AU4. In total, 23 participants chose alternative explanations for the illustration of intense laughter of Heller, with most nominations for angry and malicious laughter, as well as screaming. Borée's second illustration (No. 2) did not have any rating above a mean of 2.34 , implying that the types of laughter given only ever applied somewhat to this illustration. This illustration involves the frontalis (but no AU4) and also here schadenfreude was more pronounced than joyful laughter. Alternative explanations were crying, disgust, distressed and painful laughter.

\section{The perception of schadenfreude laughter}

Overall, the four illustrations in the schadenfreude category differed in the extent to which to which they were perceived as prototypical for schadenfreude $(F[3,216]=35.24, p<.001)$. However, only Borée's illustration was rated "mostly typical" for schadenfreude (i.e., exceeded 3.0) and the one by Rudolph No. 2 (very intense) exceeded the cut-off value of 2.50. These two illustrations also differed from each other, $F(1,216)=6.36, p<.05$. The remaining two illustrations (Huter, Rudolph No. 1) were not perceived as typical for schadenfreude at all. For Rudolph's illustration No. 1, no rating exceeded the value of 2.50.

It is informative to compare all five illustrations that received a mean rating of 2.50 or higher in schadenfreude, with this additionally being the highest rating, irrespective of the category they originally came from. While these five are generally different $(F[4,288]=$ $3.68, p<.01$ ), there were basically two blocks that differed from each other without any significant difference within. There are the high schadenfreude illustrations (intense laughter by Piderit and Heller, schadenfreude by Borée) and low schadenfreude illustrations (joyful laughter by Heller, schadenfreude laughter by Rudolph, No. $2 ; F[1,288]=14.31, p<.01)$. In 
terms of facial expression there are two variants. First, the AU4 (possibly AU9) in addition to AU6, AU7, and AU12, and an open mouth (AU25, AU26, AU27); the two more intense expressions have an AU4 of at least marked intensity. The other variant is the schadenfreude illustration by Borée that does not involve an AU4, but AU7 in extreme intensity, with a very small mouth aperture and unilateral AU15 and AU2 and a symmetric AU1. Two hypotheses about the facial features of schadenfreude laughter might be put forward. Schadenfreude displays might entail the facial expression of enjoyment with strong mouth opening (laughter), plus a sign of negative emotion (AU4, AU9). Otherwise, if this finding happens to be replicated or more expressions are found, it is perhaps a more voluntary expression lacking enjoyment, with only a slight parting of the lips, a tightening of the eyelids, and the raising of eyebrows with asymmetric action in outer eyebrow and lips corner repression in addition to an AU12.

\section{The perception of grinning}

The four illustrations of grinning differed significantly from each other in the grinning ratings $(F[3,216]=26.95, p<.001)$. Nevertheless, none of the grinning rating exceeded a mean of 3.00 or of 2.50 (Rudolph $M=2.41$; Huter $M=2.48$ ). While the grinning rating in Huter' $\mathrm{s}$ illustration was significantly higher than the other ratings, Rudolph's slight grinning illustration was considered equally representative for schadenfreude (perhaps due to the AU4) and intense laughter as it was for grinning. Borée's and Rudolph's intense grinning illustrations were not representative of grinning but were perceived as intense laughter and Borée's grinning additionally as joyful laughter.

Looking at all illustrations it is apparent than only one of the displays exceeded 3.00, namely the joyful laughter display by Huter, which was equally high in joyful laughter. Applying the more liberal, lower cut-off value of 2.50, Huter`s schadenfreude illustration is equally high in joyful and grinning. Borée's schadenfreude illustration is equally typical for schadenfreude and for grinning. It seems difficult to either encode or decode grinning independent from schadenfreude within the scope of the present illustrations.

Finally, the correlation between the facial data and the mean ratings across all 18 illustrations were inspected and proved to be instructive. For example, the intensity of Duchenne Displays (AU6 and AU12; intensity of AU12 was used as intensity estimate) correlated with the perception of joyful laughter $(r=.73, p<.01)$ and intense laughter $(r=$ $.53, p<.05)$. The presence of AU4 diminished the perception of joyful laughter $(r=-.45, p<$ .05 one tailed) and the presence of AU6 increased the intensity of perceived joyful laughter $(r$ $=.44, p<.05$ one tailed). Interestingly, the perception of intense laughter correlated negatively with the perception of grinning $(r=-.90, p<.01$; $\mathrm{df}=16)$; grinning was rated as intense in illustrations where laughter was rated as low in intensity. And overall grinning went along with the absence of AU6 $(r=-.41, p<.05$ one tailed $)$.

\section{Discussion}

Illustrations of laughter involving a DD were perceived as joyful laughter irrespective of whether they had been pre-classified as joyful or intense laughter. Thus, those authors that drew, carved, sculptured or posed a DD with open mouth were more accurate in portraying joyful laughter. The DD could also involve an AU7 (in addition to AU6 and AU12, and AU25, but only these). The joy ratings were significantly lower when the AU6 was missing or when additional facial actions were present in an illustration. Borée's illustration of grinning appears to be a puzzling exception, as the addition of AU1 and AU2 (and AU24) did not 
lower the joy ratings very much. One reason might be that participants see this (intense) laughter as a blend of joy and surprise.

The perception of intensity in joyful laughter is a function of the intensity of the facial actions involved in the DD. The material studied did not allow isolating the relative contribution of intensity of lip corner retraction, mouth opening and eye region action. Also, other laughter reached higher intensity ratings, but these were not joy-based, but further indicated schadenfreude (Heller's intense laughter) or perhaps the yet to be confirmed joysurprise blend (Borée's grinning with marked jaw drop). For the schadenfreude illustrations the intensity of the corrugator activity seems to be determining the intensity of the laugh. Thus, the postulate by Darwin (Piderit, Heller, etc.) that an additional frowning would give the appearance of a more intense laughter of joy was incorrect since it changed the perception of the general nature of the laugh. Overall, the addition of a frown led to lower perceived intensity compared to a Duchenne Display based laughter.

The results are less clear for schadenfreude. The present analysis of the historic material does not allow for a clear single hypothesis, as none of the displays were extremely prototypical. Still it is possible to narrow down the possibilities. One prototype derived from the material is a joyful face with an added AU4 (and AU9). This goes along with the idea that schadenfreude is a blend of the positive emotion of joy with some aspects of negative emotion (e.g., anger, malice or taunt).

None of the proposed grinning expressions were perceived as such. It might be that none of the illustrations conveyed a convincing grinning expression, or that the rating (or the instructions) did not work that well for the grinning category. The AU12 without the AU6 in Huter's illustration of the joyful laugh yielded the highest prototypicality rating. Perhaps some people picked up the lack of the AU6 and perceived it as grinning while the others saw it as joyful. Thus, elongated lip corners and the bared teeth might be perceived as typical for grinning--in line with Darwin's descriptions. However, the mean ratings for grinning were too low to speculate to have found all the elements of grinning.

\section{General Discussion}

Overall, the studies allow four major conclusions. Joyful and intense laughter were recognized when they entailed the Duchenne Display. Historic authors grasped the key features of joyful laughter correctly, whereas the intensity of laughter was only captured correctly by Rudolph (1903). Thus, valid knowledge on facial expression of emotion was present among these historic authors (for the laughter categories where current research has identified the specific expressions). Their expressions were also identified by a current sample of laypeople.

Darwin's claim of the involvement of the AU4 in intense laughter was not supported, although most of his fellow authors included it. The question is whether authors who did not know Bell's and Piderit's work would have included the AU4 as well. Furthermore, the question arises as to where does the lowering of the eyebrows come from? Is it an attempt at regulating an intense and possibly long laughter? Is the AU4 a sign of an emotion blend or a regulator? Additionally, the association of the AU4 with negative affect might have led to the various alternative interpretations such as anger, malice or skeptical laughter and the high means in grinning and schadenfreude. Ruch and Ekman (2001) quote research using facial electromyography that show that during regular laughter the muscle tone is actually lowered in the corrugator but it is enhanced during episodes of pathological laughter. 
The hypothesis put forward in the schadenfreude laughter is in line with Ekman's (2003) hypothesis that schadenfreude is a facet of joy and hence (if freely expressed) involves a DD. However, in Western cultures, schadenfreude is considered an inappropriate response, as one is not supposed to gloat over one's success combined with enjoying the misfortune of others (Ekman, 2003). Therefore, display rules (Ekman \& Friesen, 1971) may forbid the free expression of joy when it is elicited by others' misfortunes. Modulation, simulation, neutralization or masking of the expression can be expected (Ekman, 1985). Consequently, the intensity of the DD will be lowered and some "noise" will be added to the face, which will impair the recognition of sheer joy by others. This might involve some elements of smile controls (i.e., lower intensity lip corner retraction and less opening of the mouth), additional covering actions like looking away, hand on mouth, or, as in the other observed variant, adding salient voluntary actions that change the expression of joy in the mouth and eye region (as in Borée's illustration). This might be a combination of the expression of joy and voluntary actions. These findings are not antagonistic to Ekman's idea of schadenfreude being a facet of joy (and represented by a DD); the crucial test will be what facial expression people will show when they actually experience schadenfreude. It appears that the investigation of the historic illustration (i.e., still photos) was not overly helpful, and the investigation of a video clip portraying schadenfreude laughter is necessary. Such a study should also test the alternative hypothesis (based on Darwin's claims) that laughter may blend with or mask negative states. Again, this needs experimental control over the expression and the study whether schadenfreude is a blend of happy and taunted laughter.

Only one illustration represented grinning, and this one only had only few features described by Darwin: retraction of lip corners and upper teeth row is visible. As none of the grinning illustrations were perceived as grinning, it is difficult to tackle what exactly the grinning laughter would involve in terms of facial actions. These illustrations had the stronger reduction of eye aperture (as predicted by Darwin), but they also involved changes in the forehead. Thus, the prediction based on Darwin's description still hold as the material in the present study was not optimal to test the hypotheses. It is also possible that there are more types of grinning, as grinning may be associated with malice or signal stupidity (or is aimed at signalling it voluntarily). Based on own posing we hypothesize that some types of (voluntary) grinning involve the appearance of a prolonged mouth (e.g., the "Cheshire cat grin"), generally little involvement of the eyes, and a fixed prolonged apex. Yet, especially the last appearance change cannot be identified in static photos. Clearly, more work is needed to investigate grinning and its meaning, as identifying descriptive adjectives typically going along with grinning suggest that grinning may not be linked to one emotion or emotion blend, but entails emotional, as well as cognitive elements (such as grinning stupidly or maliciously).

The results of the current study are limited by the historic authors method to collect their different categories of laughter. The method of free observation is problematic as quick changes during laughter are maybe overlooked or observers misinterpret actions. Some authors tried to avoid these problems by posing laughter (see Borée, 1899; Huter, 1925, Leonhard, 1950; Rudolph, 1903). However, this approach entails the challenge that some facial muscles are not easy to move deliberately. Therefore, posed expressions presumably do not contain all facial changes occurring in spontaneous expressions, or they represent stereotypical displays. A somewhat more objective method is to describe the muscles involved in laughter and consequent changes in the facial expression. Still, these results are limited by wrong "translation" rules. For example, often the risorius muscle was held responsible for the facial changes due to the zygomatic major muscle. The use of films would therefore be an appropriate method to investigate laughter as it allows showing the development of a laughter event from the onset, apex and offset over the natural duration of 
time. Furthermore, it allows for sound emission to be located in the event. It might be that laughter is better recognized when its vocalization is audible (e.g., Szameitat et al., 2010).

After this initial period of pioneering research by the aforementioned authors, not much further research was undertaken. So far, no study with the objective of distinguishing further types of laughter has been conducted. Empirical studies of electromyographic activity of facial muscles during laughter identified a number of muscles to be involved in laughter that exceeded the one defining the Duchenne Display (see Ruch \& Ekman, 2001). Thus, there might be further morphologically different types of laughter. Future directions show the growing interest in the technologies of laughter (e.g., avatars and virtual agents joining in with users laughter, Urbain et al., 2009; robots laughing, Becker-Asano et al., 2010). There is therefore an urgency to clarify how many types of laughter can be distinguished at a morphological level. Whereas the investigation of historic illustrations of laughter could not solve this problem, we hope to have opened the discussion for following empirical studies.

\section{Notes}

* The authors would like to thank Katharina Klohe for helping with parts of the data collection and Francisca Stoffel and Annette Weber for the control coding.

** The research leading to these results has received funding from the European Union Seventh Framework Program (FP7/2007-2013) under grant agreement $n^{\circ} 270780$ (ILHAIRE project).

[1] A further study with 87 participants showed that out of 9 emotions, this illustration had a mean surprise rating of $M=3.20$ on a six-point rating scale, with surprise significantly differing from the eight other emotions including joy $(M=1.85)$.

*** Address for correspondence: Willibald Ruch, University of Zurich, Institute for Psychology, Personality and Assessment, Binzmühlestrasse 14, Box 7, CH-8050 Zürich,w.ruch@psychologie.uzh.ch

\section{References}

Andrews, R. J. (1964). The displays of the primates. In J. Buettner-Janusch (Ed.), Evolutionary and genetic biology of primates (Vol. II, pp. 228-309). New York: Academic Press.

Becker-Asano, C., Kanda, T., Ishi, C., \& Ishiguro, H. (2010). Studying laughter in combination with two humanoid robots. Artificial Intelligence \& Society, 26, 291-300.

Bell, C. (1844). The anatomy and philosophy of expression as connected with the fine arts. London: John Murray.

Borée, A. (1899). Physiognomische Studien [Physiognomic studies]. Stuttgart: Julius Hoffmann.

Darwin, C. (1872). The expression of the emotions in man and animals. London: John Murray.

Dearborn, G. V. N. (1900). The nature of the smile and laugh. Science, 11, 851-856.

Duchenne (de Boulogne), G.-B. (1876). Mécanisme de la physionomie humaine. Atlas. Deuxième édition. Paris: J.-B. Bailliere et Fils.

Ekman, P. (1985). Telling lies. Clues to deceit in the marketplace, politics, and marriage. New York: W.W. Norton.

Ekman, P. \& Friesen, W. V. (1971). Constants across cultures in the face and emotion. Journal of Nonverbal Behavior, 6, 238-252.

Ekman, P., Davidson, R. J., \& Friesen, W. V. (1990). The Duchenne smile: Emotional expression and brain physiology II. Journal of Personality and Social Psychology, 58, 342-353.

Ekman, P., Friesen, W. V., \& Hager, J. C. (2002). Facial Action Coding System: A technique for the measurement of facial movement. Palo Alto: Consulting Psychologists Press.

Frank, M. G. \& Ekman, P. (1993). Not all smiles are created equal: The differences between enjoyment and non-enjoyment smiles. Humor: International Journal of Humor Research, 6, 926.

Fridlund, A. J. (1994). Human facial expression. An evolutionary view. New York: Academic Press. 
Hall, G. S. \& Allin, A. (1897). The psychology of tickling, laughing, and the comic. The American Journal of Psychology, 9, 1-41.

Heller, H. V. (1902). Grundformen der Mimik des Antlitzes [Basic forms of the mimic]. Vienna: Anton Schroll.

Herland, L. (1938). Gesicht und Charakter. Handbuch der praktischen Charakterdeutung [Face and character. Handbook of practical interpretation of the character]. Vienna: Saturn.

Huber, T. (2011). Enkodierung und Dekodierung verschiedener Arten des Lachens. Eine FACS basierte Studie mit Schauspielern [Encoding and decoding of different types of laughter. A FACS based study with actors]. Unpublished thesis, University of Zurich, Switzerland.

Huter, C. (1925). Physiognomik und Mimik [Physiognomy and mimic]. Schwaig bei Nürnberg, Germany: Carl-Huter-Verlag.

Keltner, D. (1995). Signs of appeasement: Evidence for the distinct displays of embarrassment, amusement, and shame. Journal of Personality and Social Psychology, 68, 441-454.

Keltner, D., \& Bonanno, G. A. (1997). A study of laughter and dissociations: distinct correlates of laughter and smiling during bereavement. Journal of Personality and Social Psychology, 73, 687-702.

Kemper, T. D. (1987). How many emotions are there? Wedding the social and the autonomic components. The American Journal of Sociology, 93, 263-289.

Lange, F. (1937). Die Sprache des menschlichen Antlitzes [The language of the human face]. Munich, Germany: J. F. Lehmann.

Leonhard, K. (1950). Der menschliche Ausdruck in Mimik, Gestik und Phonik [Human expression in mimic, gesture, and phonation]. Leipzig: Barth.

Lersch, P. (1932). Gesicht und Seele: Grundlinien einer mimischen Diagnostik [Face and psyche: outline of mimic diagnostics]. Munich, Germany: Reinhardt.

Piderit, Th. (1867). Mimik und Physiognomik [Mimic and physiognomy]. Detmold, Germany: Verlag der Meyerschen Hofbuchhandlung. [Original work published 1867]

Plessner, H. (1941). Lachen und Weinen [Laughing and crying]. Bern, Switzerland: Franke.

Ruch, W. (1990). Die Emotion Erheiterung: Ausdrucksformen und Bedingungen [The emotion of exhilaration: Forms of expression and conditions.] Unpublished habilitation thesis, University of Düsseldorf, Germany.

Ruch, W. (1993). Exhilaration and humor. In M. Lewis \& J. M. Haviland (Eds.), The Handbook of Emotions (pp. 605-616). New York: Guilford Publications.

Ruch, W., \& Ekman, P. (2001). The expressive pattern of laughter. In A. W. Kaszniak (Ed.), Emotion, qualia, and consciousness (pp. 426-443). Tokyo: Word Scientific Publisher.

Rudolf, H. (1903). Der Ausdruck der Gemütsbewegungen des Menschen [The expression of the emotions in man]. Dresden, Germany: Gerhard Küthmann.

Schack, S. (1890). Physiognomische Studien [Physiognomic studies]. Jena: Hermann Costenoble.

Strehle, H. (1954). Mienen, Gesten und Gebärden: Analyse des Gebahrens [Expressions, gestures and looks: analysis of behavior]. Munich: Reinhardt.

Sumitsuji, N. (1967). Electromyographic studies on facial expression. Psychiatria et Neurologia Japonica, 69, 1101-1119.

Szameitat, D. P., Alter, K., Szameitat, A. J., Wildgruber, D., Sterr, A., \& Darwin, C. J. (2010). Acoustic profiles of distinct emotional expressions in laughter. Journal of the Acoustical Society of America, 126, 354-366.

Urbain, J., Niewiadomski, R., Bevaqua, E., Dutoit, T., Moinet, A., et al. (2009). AV Laughter Cycle. Journal on Multimodal User Interfaces, 4, 47-58. 